

\title{
Particle diffusion in a spheromak
}

\author{
D.D. Meyerhofer ${ }^{1}$, F.M. Levinton ${ }^{2}$, and M. Yamada
}

\author{
Ptinceton Plasma Physics Laboratory \\ Princeton University \\ James Forrestal Campus \\ Princeton NJ 08544
}

\begin{abstract}
The local carbon particle diffusion coefficient was measured in the Proto S-1/C spheromak using a test particle injection scheme. When the plasma was not in a force-free Taylor state, and when there were pressure gradients in the plasma, the particle diffusion was five times that predicted by Bohm and was consistent with collisional drift wave diffusion. The diffusion appears to be driven by correlations of the fluctuating electric field and density. During the decay phase of the discharge when the plasma was in the Taylor state, the diffusion coefficient of the carbon was classical.

1 Present address, Lab of Plasma Studies, Upson Hall, Cornell I'niversity,

${ }^{2}$ On assignment from JAYCOR, Torrance Ca. 90503
\end{abstract} Ithaca NY 14853 
The spheromak ${ }^{1}$ is a compact toroidal magnetic fusion device with an aspect ratio close to one. It has features which are favorable for reactor design. The lack of magnetic field coils linking the plasma allows the trarslation and compression of the plasma, as well as a simple reactor blanket design. ${ }^{2,5}$ The confining magnetic fields are generated primarily by the currents carried in the plasma, allowing high values of engineering $\beta$ to be obtained. The engineering $\beta$ is the ratio of the plasma pressure to that applied by external magnetic fields, and higher values may reduce reactor costs.

Spheromaks, and the closely related Reversed Field Pinches, have the tendency to relax to magnetic field configurations which are close to the minimum energy states predicted by Taylor. ${ }^{4}$ The minimum energy states, subject to the conservation of the global helicity, are force-free,

$$
\vec{j} \times \vec{B}=\vec{\nabla}_{p}=0
$$

and satisfy,

$$
\vec{\nabla} \times \vec{B}=k \vec{B}
$$

with $k$ a constant throughout the plasma. It is worth noting that a plasma device with $p=0$ at the edge cannot be in the Taylor state and have a finite temperature and density at the center, so the process of relaxing towards the Taylor state may enhance the energy loss mechanisms of the plasma. One energy loss mechanism is convection, the energy carried out of the 
plasma by particles which have a tinite confinement time.

This Letter presents the results of direct measurement of the local carbon particle diffusion coefficient on the Proto S-1/C spheromak. ${ }^{5}$ During the decay phase of the discharge, the diffusion of the carbon ions could be explained classically. During the relaxation phase of the discharge, the anomalous perpendicular diffusion coefficient, $D_{\mathrm{an}}=D_{\perp}-D_{\mathrm{cl}}$, was approximately five times that predicted by $\mathbf{B o h m}^{*}$ and was caused by electric field Auctuation- induced velocities. The electric field fluctuations and the value of $D_{\text {an }}$ were consistent with those expected from collisional drift waves.

For carbon ions in a hydrogen plasma, the classical diffusion coefficient is, ${ }^{7,8}$

$$
D_{\mathrm{cl}}=3.5 \times 10^{-4} \frac{n_{\mathrm{H}} \ln \Delta}{\sqrt{T_{\mathrm{H}}} B^{2}},
$$

where the Coulomb logarithm is in $\Lambda=23-\ln \sqrt{n_{\mathrm{H}}} / T^{\frac{3}{2}}$. The spheromak is a $q<1$ device, so that neoclassical transport is unimportant.

Bohm ${ }^{6}$ proposed that fluctuating electric fields in the plasma would lead to a diffusion coefficient larger than classically predicted, and would scale inversely with the magnetic field,

$$
D_{B}=\alpha \frac{c T}{e B}
$$

Bohm ${ }^{8}$ took $\alpha=1 / 16$. It has been found that the diffusion coefficient due to convective cells, has a similar form as Eq. (4) ${ }^{9-11}$ Hassam and Kulsrud ${ }^{13}$ pointed out that in a toroidal system the convective cell is an interchange 
mode to which spheromaks are expected to be unstable at relatively small values of plasma $\beta .^{1}$

The Proto S-1/C spheromak plasma ${ }^{5}$ was formed inductively using a Alux core which has minor and major radii of 6 and $30 \mathrm{~cm}$, respectively. The plasma typically had a major radius of $16 \mathrm{~cm}$ and a minor radius of $12 \mathrm{~cm}$. The plasmas, which lasted for $100 \mu \mathrm{sec}$, had magnetic field strengths of $1-2 \mathrm{kG}$, and electron temperatures and densities of $8 \mathrm{eV}$ and $1 \times 10^{14} \mathrm{~cm}^{-3}$, respectively. The spatial and temporal evolution of the electron temperature and density were measured with a triple Langmuir probe. ${ }^{13}$ The electron-ion equilibration time is roughly $5 \mu \mathrm{sec}$ so the ion temperature is assumed to be equal to the electron temperature. By quasineutrality the ion density was assumed equal to the electron density. The ratio of kinetic to magnetic pressureg in the plasma, $\beta$, was roughly $10 \%$.

The plasma lifetime can be divided into distinct phases. After the breakdown of the initial fill gas, the plasma undergoes a violent relaxation towards the minimum energy Taylor state.,14 During this phase, there are large magnetic fluctuations, $\frac{6 B}{B} \gtrsim 10 \%$, throughout the plasma. The magnetic fluctuations were measured with internal and external, glass encased probes. The observed fluctuation levels were unaffected by the number of probes in the plasma. At roughly $30 \mu \mathrm{sec}$, there is a large drop in the to tal poloidal flux in the plasma, accompanied by externally observed global magnetic modes, with poloidal and toroidal mode numbers, $m=1$, and 
$n=2 \sim 4$. These appear to be due to the relaxation of resonant modes ${ }^{14,15}$ as was observed in the S-1 spheromak. ${ }^{14}$ After the reconnection of the modes, the plasma, with $\vec{\nabla}_{p} \neq 0$, continues to evolve towards the Taylor state, which has $\vec{\nabla} p=0$, while the magnetic fluctuation level at the center of the plasma was less than $1 \%$. This relaxation phase of the discharge, lasted from $30 \sim 60 \mu \mathrm{sec}$. From $60 \sim 100 \mu \mathrm{sec}$, the plasma was in the forcefree Taylor state, ${ }^{1,4}$ referred to as the decay phase of the discharge, as the currents in the plasma were no longer externally driven. After $100 \mu \mathrm{sec}$, the plasma was terminated by a global, $n=1$, tilt instability. ${ }^{16}$

The carbon particle diffusion coefficient was measured by injecting a delta function source of carbon ions at the midplane of the plasma and observing the evolution of the injected density spectroscopically. The technique. which has been described in detail elsewhere, ${ }^{17}$ allows both $D_{\|}$ and $D_{\perp}$ to be locally measured. A schematic of the basic setup is shown in Fig. 1. A probe, with two graphite tips is discharged in the plasma, injecting primarily CII jons (spectroscopic notation) into the center of the plasma. The cross-field evolution of the injected density is determined by the perpendicular diffusion coefficient. The gradient lengths and time scales for change of the injected carbon ions were shorter than those in the background plasma so that the changes in the background pi.msma were ignored. This was also consistent with the short equilibration times in the plasma, and the small amount of carbon injected compared to the amount 
in the device. The analysis of the diffusion coefficients included the effect of convection and ionization, with all of the convection observed due to the motion of the magnetic surfaces.

During the decay phase of the discharge, the measured diffusion coefficients on the closed flux surfaces were compared directly to the classical values. For all of the discharges examined the electron temperature had a constant value of $8 \mathrm{eV}$ within the error bars. Figure 2 shows the electron density versus magnetic field during the decay phase of the discharge. The electron density can be taken as a linear function of the magnetic field strength leading to a classical carbon diffusion coefficient of

$$
D_{\mathrm{cl}}=\frac{1.3 \times 10^{8}}{B}\left(\mathrm{~cm}^{2} / \mathrm{sec}\right),
$$

with $B$ in Gauss with a roughly $30 \%$ error. The measured values of the carbon diffusion coefficient in the decay phase are compared to this value in Fig. 3. Also shown is the calculated value for $D_{\perp}=D_{\mathrm{el}}+5 D_{\mathrm{Bohm}}$, which is discussed below.

The diffusion coefficient during the relaxation phase of the discharge was higher than classically predicted. Figure 4 shows the carbon diffusion coefficients measured during the relaxation phase compared to $D_{\perp}=D_{\mathrm{cl}}+$ $5 D_{\text {Bohm. }}$ During this phase of the discharge, the density was independent of the magnetic field strength so the classically predicted diffusion coefficient 
was $D_{\mathrm{el}}=1.25 \times 10^{11} / B^{2}$. In this case, $D_{\mathrm{Bohm}}$ includes the factor of $1 / 16$,

$$
5 D_{\text {Bohm }}=\frac{2.5 \times 10^{8}}{B}\left(\mathrm{~cm}^{2} / \mathrm{sec}\right)
$$

with a $40 \%$ error. At this time, the magnetic fluctuation level was less than 1\%. Thus, it appears that a combination of classical and Bohm diffusion is sufficient to explain the measured carbon diffusion coefficients.

A triple probe was used to measure the correlations of the electric field and density fluctuations. ${ }^{18}$ The electric field in the direction perpendicular to the magnetic field in the flux surface was measured with a pair of tips, while a third measured the density. The particles undergo an average $\vec{E} \times \vec{B}$ drift when the fluctuations are correlated, ${ }^{18}$

$$
v_{\tilde{E} \times \vec{B}}=\frac{c}{B}<\frac{\delta n}{n} \delta \vec{E}>\text {. }
$$

The measurements of the correlation of the electric field and density fluctuations led to velocities, $v_{\bar{E} \times \tilde{B}} \sim 6 \times 10^{4} \mathrm{~cm} / \mathrm{sec}$ during the relaxation phase of the discharge. A diffusion coefficient can be estimated from the velocity, ${ }^{18} D_{\text {an }} \sim v_{\bar{E} \times \bar{B}} \frac{n}{\sqrt{n}}$. With a density scale length of $5 \mathrm{~cm}$, this led to an estimate of $D_{\perp} \sim 3 \times 10^{5} \mathrm{~cm}^{2} / \mathrm{s}$, comparable to the diffusion coefficients observed. The average value of the fluctuation-induced velocity during the decay phase of the plasma was $v_{\bar{E} \times \bar{B}}=0.6 \pm 0.6 \times 10^{4} \mathrm{~cm} / \mathrm{sec}$. One possible origin of $v_{E \times B}$ was collisional drift waves.

There are pressure gradients across tiux surfaces during the relaxation phase of the discharge. Collisional drift waves are unstable in inhomoge- 
neous plasmas with high collisionality. ${ }^{10}$ Their source of free energy is the density gradient, while the collisions affect the phase between the wave's electric field and density fluctuations, causing a positive correlation. ${ }^{20}$ In the absence of collisions, or other dissipation, this mode, driven only by the density gradient, is stable.

The largest growth rate occurs at roughly $\gamma \sim \omega^{*}$, where

$$
\omega^{*} \equiv \frac{k_{1} c T_{e}}{e B} \frac{1}{T_{n}}
$$

is the diamagnetic drift frequency and

$$
\frac{1}{r_{n}} \equiv \frac{1}{n} \frac{\partial n}{\partial r}
$$

is the density gradient scale length. In the Proto S-1/C spheromak, $r_{n} \sim$ $5 \mathrm{~cm}$ during the relaxation phase. The perpendicular wave number, $k_{L}$, was estimated from $\delta \vec{E}_{\perp} \sim \vec{k}_{\perp} \delta \phi$, measured with the triple probe, to be $2 \mathrm{~cm}^{-1}$. The diamagnetic frequency was $\omega^{*} \sim 3 \times 10^{5} \mathrm{rad} / \mathrm{sec}$, the same order of magnitude as the frequency of the electric field fluctuations observed.

For $\gamma \sim \omega^{*}, D_{\mathrm{d} r}$ can be estimated from the experimental parameters using Kadomtsev's mixing-length argument ${ }^{19}$ as,

$$
D_{\mathrm{dr}}=\frac{p_{i} v_{i}}{k_{\perp} \tau_{n}} \sim \frac{3}{16} \frac{c T}{e B}
$$

in good agreement with the $\frac{5}{16}$ observed.

Thus, it appears that a combination of classical and Bohm diffusion is sufficient to explain the measured carbon diffusion coefficients. The lack of 
anomalous (i.e., nonclassical) diffusion on the closed flux surfaces is to be expected because of the large value of the classical diffusion coefficient, and because there was no pressure gradient across the closed flux surfaces within the errors of the measurement and, hence, there was no free energy to drive anomalous diffusion. During the relaxation phase of the discharge, there were fressure gradients throughout the plasma, and these provided the free energy necessary to drive instabilities which led to anomalous diffusion.

In the S-1 and CTX spheromaks, it was found that convective energy losses were important compionents of the plasma energy balance. ${ }^{21,22}$ The values of the particle diffusion coefficients of $5 D_{\mathrm{Bohm}}$ are sufficient to explain the particle confinement times observed in S-1 ${ }^{23}$ and $\mathrm{CTX}^{21}$ during the periods when there were pressure gradients in the plasma.

Useful discussions with C. Barnes, R.J. Goldston, F.W. Perkins, and S. Zweben are gratefully acknowledged. This work was supported by US Department of Energy contract \# DE-ACO2-76-CHO-3073. 


\section{References}

${ }^{1}$ M. N, Rosenbluth and M. N. Bussac, Nucl. Fusion 19, 489 (1979).

${ }^{2}$ M.N. Bussac, H.P. Furth, M. Okabayashi, M.N, Rosenbluth, and A.M. Todd, "Low-Aspect-Ratio Limit of the Toroidal Reactor: The Spheromak," in Plasma Physics and Controlled Nuclear Fusion Research, 1973 (IAEA, Vienna, 1979), Vol. III (Innsbruck Conference), p. 249.

${ }^{3}$ M. Katsurai and M. Yamada, Nucl. Fusion 22, 1407 (1982).

I. B. Taylor, Rev. Mod. Phys. 58, 741 (1986).

${ }^{5}$ M. Yamada, H. P. Furth, W. Hsu, A. Janos, S. Jardin, M. Okabayashi, J. Sinnis, T. H. Stix, and K. Yamazaki, Phys. Rev. Lett. 46, 188 (1981).

${ }^{e}$ D. Bohm, E.H.S. Burhop, and H.S.W. Massey, "The use of Probes for Plasma Exploration in Strong Magnetic Fields, ${ }^{n}$ in The Characteristics of Electrical Discharges in Mangetic Fields, edited by A. Guthrie and R.K. Wakerling (McGraw-Hill, New York, 1949), p. 13.

7S.I. Braginskii, Transport Processes in a Plasma (Consultants Bureau, New York, 1965), Vol. 1 of Reviews of Plasma Physics.

${ }^{8}$ F. L. Hinton, "Collisional Transport in Plasma," in Handbook of Plasma Physics, Vol. 1 Basic Plasma Physics, edited by A.A. Galeev and R. N. Sudan (North-Holland Publishing Co., Amsterdam, 1983), p. 148. 
9 J.M. Dawson, H. Okuda, and R.N. Carlile, Phys. Rev. Lett. 27, $491(1971)$.

${ }^{10}$ J.B. Taylor and B. McNamara, Phys. Fluids 14, 1492 (1973).

${ }^{11}$ R.Z. Sagdeev, V.D. Shapiro, and V.I. Shevchendo, Sov. J. Plas. Phys. 4, 306 (1978).

${ }^{12}$ A.B. Hassam and R.M. Kulsrud, Phys. Fluids 22, 2097 (1979).

${ }^{13}$ S.L. Chen and T. Sekiguchi, J. Appl. Phys. 36, 2363 (1965).

${ }^{14}$ A. Janos, G. W. Hart, and M. Yamada, Phys. Rev. Lett. 55, 2868 (1985).

${ }^{15}$ A.G. Sgro, A.A. Mirin, and G. Marklin, submitted to Phys. Fluids.

${ }^{16}$ S. C. Jardin, M. S. Chance, R. L. Dewar, R. C. Grimm, and D. A. Monticello, Nucl. Fusion 21, 1203 (1981).

${ }^{17}$ F.M. Levinton and D.D. Meyerhofer, Rev. Sci. Instrum. 58, 1393 (1987).

${ }^{18}$ P.C. Liewer, Nucl. Fusion 25, 543 (1985).

${ }^{19}$ B.B. Kadomtsev, Plasma Turbulence (Academic Press, London, 1965).

${ }^{30}$ F.F. Chen, Phys. Fluids 7, 949 (1964).

${ }^{21}$ Cris W. Barnes, H. W. Hoida, I. Henins, J. C. Fernández, T. R. Jarboe, and G. J. Marklin, Phys. Fluids 28, 3443 (1985). 
${ }^{22}$ F.M. Levinton, D.D. Meyerhofer, R.M. Mayo, Y. Ono, Y. Ueda, and M. Yamada, Bull. Am. Phys. Soc. 32, 1735 (1987).

${ }^{23}$ R. Mayo, F.M. Levinton, and D.D. Meyerhofer, Bull. Am. Phys. Soc. 32, 1735 (1987). 


\section{Figures}

FIG. 1. Schematic of the Carbon injection scheme to measure the particle diffusion coefficient.

FIG. 2. Measured electron densities versus magnetic field strength during the decay phase of the discharge.

FIG. 3. Comparison of the measured $D_{\perp}$ to the classically predicted one during the decay phase $(\geq 60 \mu \mathrm{sec})$ of the discharge. Also shown is the calculated value for $D_{\perp}=D_{c 1}+5 D_{\text {Bohm }}$.

FIG. 4. Measured $D_{\perp}$ during the relaxation phase $(t<60 \mu \mathrm{sec})$ compared to $D_{\perp}=D_{\mathrm{cl}}+\mathbf{5} D_{\mathrm{Bohm}}$. In this case, $D_{\mathrm{Bohm}}$ includes the factor of $1 / 16$. The classically predicted diffusion coefficient is also shown. 


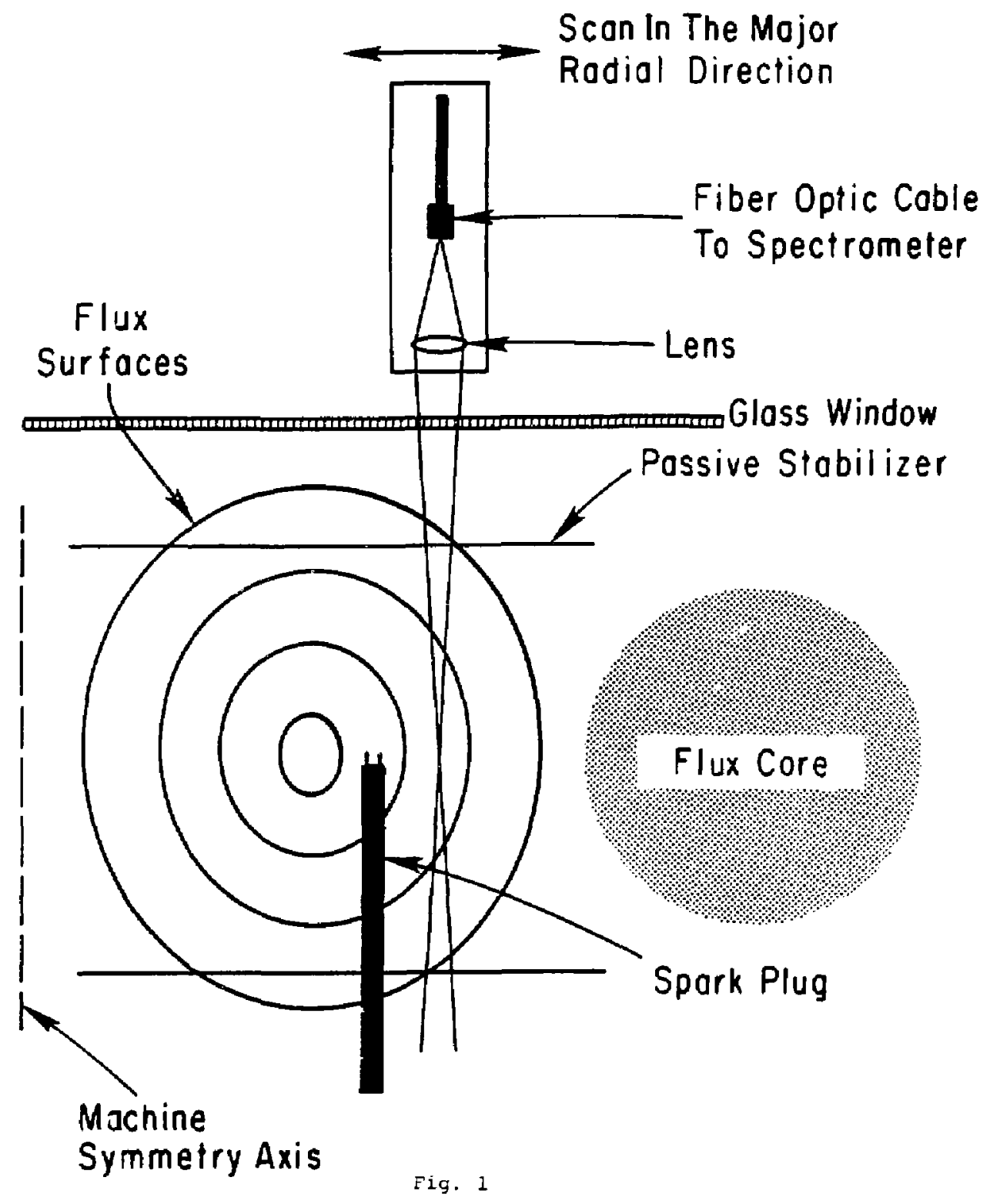




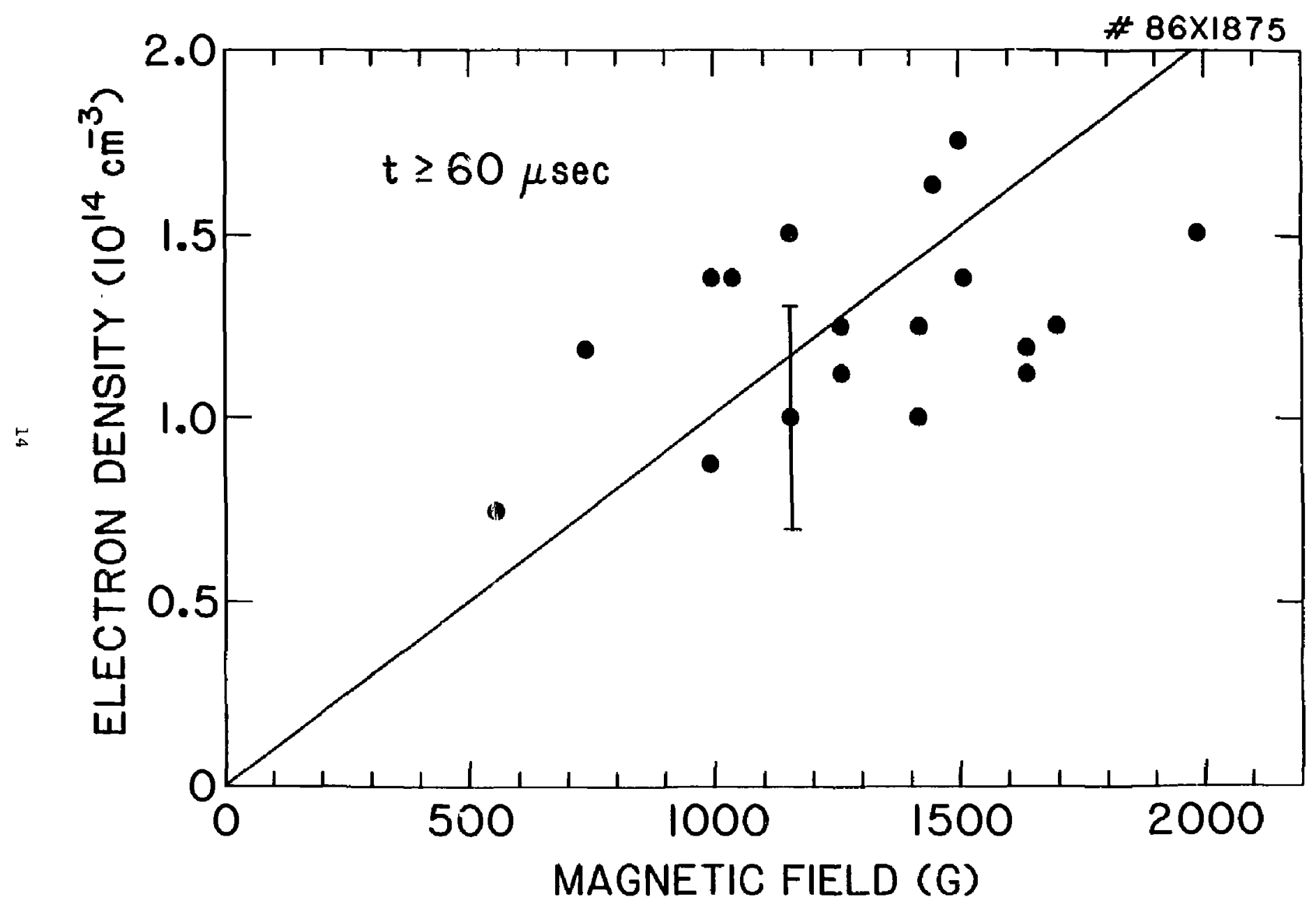

big. = 


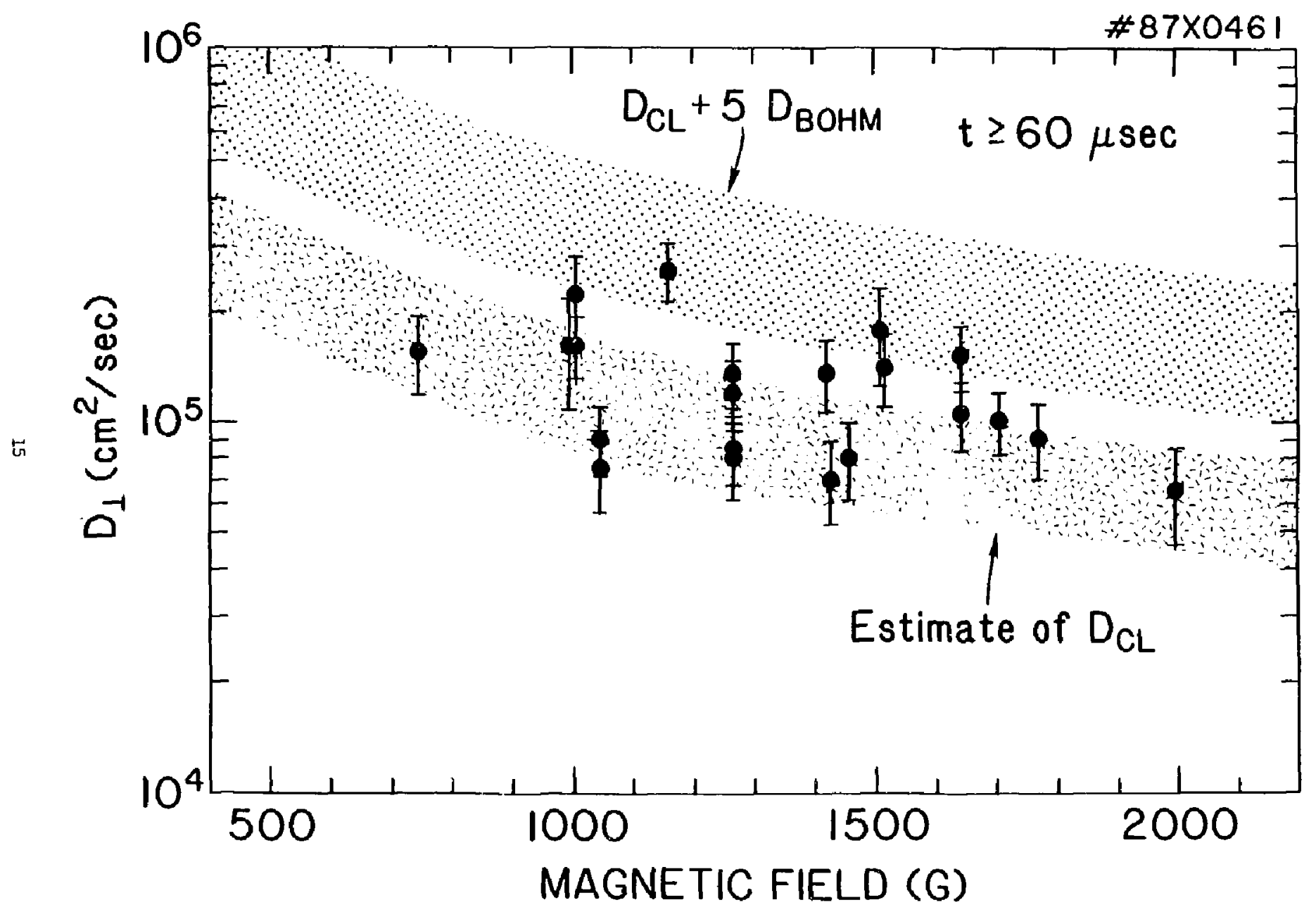




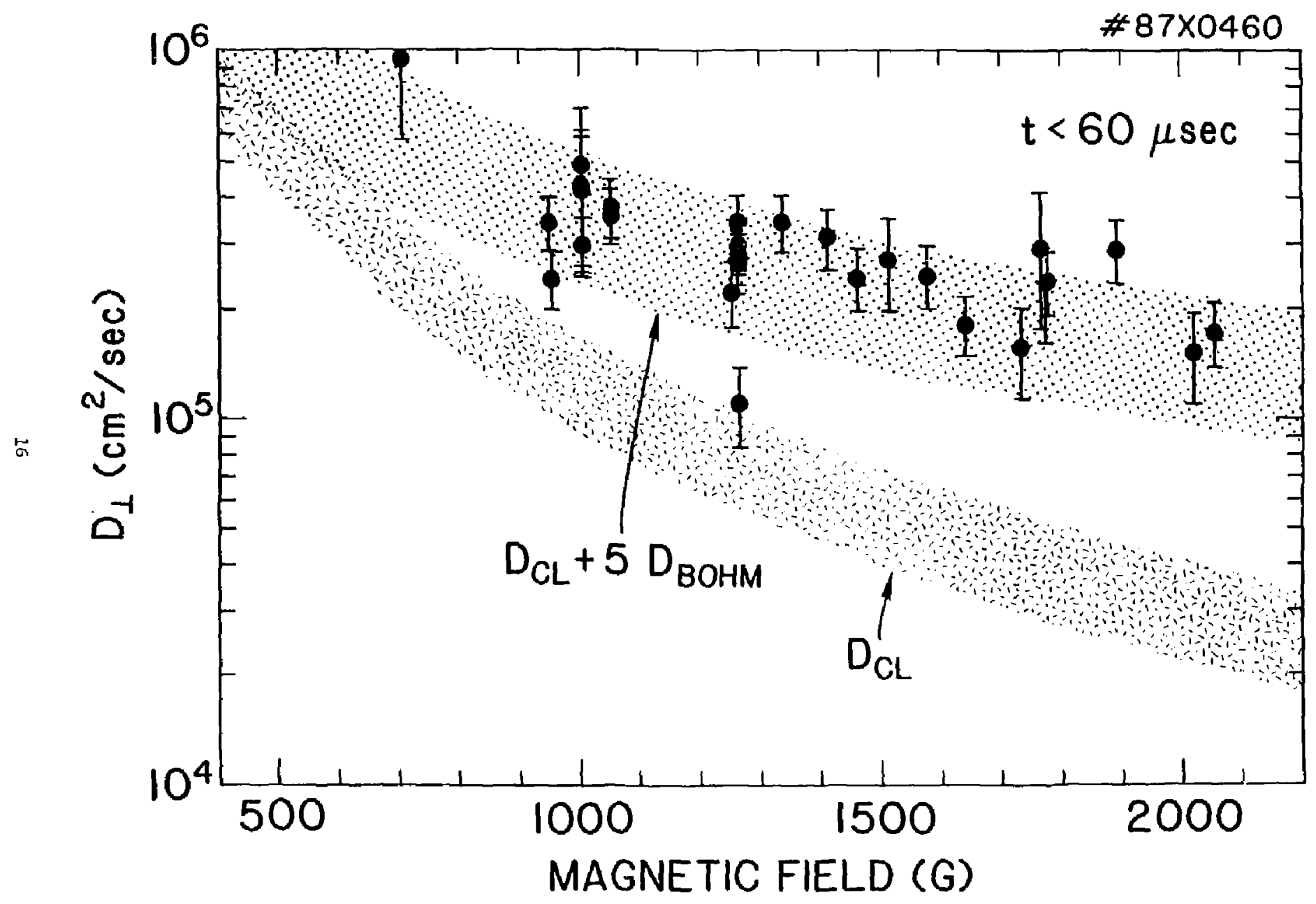


Dr. Frank J. Paaloni, Jniv of Wol longong, AUSTRAL1A Prot. M.H. Erennan, Univ Sydrey, AUSTRALIA Plasma Researeh Lab., Australian Nat. Univ., AUSTRALIA Prot, I.R. Jones, FI inders Univ., AUSTRALIA Prof. F. Cap, inst Theo Phys, AUSTRIA Prot. M. Heinaler, Irstitut fur Theoretische Physik, Austria M. Goossens, Astranomisch instituLt, BELGILM Ecole Royale Militaire, Lab de Phys PIasmas, BELGIUM Commission-Eurogean, Dg-X11 Fusion Prog, BELGium Prof. R. Boucique, Laboratorium voor Natuurkunde, BELGIUM Dr. P.H. Sakanaka, Instituto Fisica, BRAZIL instituto De Pesquisas Espaciasi-INPE, ERAZIL Doeuments Office, Atomic Energy of Canada Limited, CANADA Or. M.P. Bachynski, MPE Technologies, Ine., CANADA Dr. H,H. Skarsgard, University of Saskatehewan, CANADA Dr. H. Jarnard, University of British Columbia, CANADA Frof. J. Teichmann, Univ. of Montreal, CAMADA Prot. 5.A. Sreenivasan, University of Calgary, CANADA Jrot. Truor w. Johnston, INAS-Energie. CANAOA Dr. C.R. James, Univ. of Alberta, CANADN Dr. Peter Lukac, Komenskeho Univ, CZECHOSLOVAKIA The Librarian, Cul ham Laboratory, ENGLANO The Librarian, Ruther ford Appleton Laboratory, ENGL,AND Mrs. S.A. Hutchinson, JET Library, ENGLAND c. Wouttet, Lab. de Physique des Milieux Ionisés, france 3. Rzdet, CEN/CADARACHE - Bat 506, france Univ. of leannina, Library of Physics Dept. GREECE Dr. Tom Mual, teademy sibilographic Sor., hong kONG Preprint Library, Hungarian Acadeny of Sciences. HUNGARY Dr. 3. Dasqudta, Saha Inst of Nucl. Phys., INOIA Dr. P. Kaw, Instiqute for Plasme Research, INDIA Dr, Philip Rosenau, Israel Inst. Tech, ISRAEL Liorarian, Int'l Cer iheo Phys, ITALY

Prot. G. Rostagni, Univ Oi Padova, I TALY

Miss Clelia De Falo, Assoc EURATON-ENEA, ITALY gialioteca, Instituto di fisica del Piasma, I TaLY Dr, 4, ramato, Tosnito Ras o Dev, JafaN Prat. I. Kawakani, Atonic Energy Res. Institure, JAPAN Prot, Kyoji Nisnikawa, Univ of Hirosnima, JAPan Direc, Dept. Large Tokanak Ros. JAERI, JAPAN Prot. Setoshi Itoh, Kyushly University, JaPAN Research Info Center, Nagoya University, JAPAN Prat. S. Tanaka, Kyoto University, JAPAN Library, Kyoto University, JAPAN Prot. NObuyuki I nove. University of Tokyo, JAPan S. MOri, JAERI, JAPAN Liorari $3 n$, Lorea Advanced Energy Res. Institute, KOREA Prot. D.i. Choi, Ady. Inst Sci s Tech, KOREA Prot. 3.S. Liley, University af Waikato, NEA ZEALAND Institute of Plasna Physics, PECPLE'S REPUBLIC OF CHINA. Librarian, Institute of Phys., PEOfLE'S REPUBLIC OF CHINA

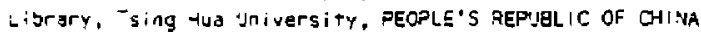

Z. Li, Southwest Inst. Physics, PEOPLE'S REPUBLIC OF CHINA Prof. J.A.C. Cabral, Inst Superior Tectico, PORTUGAL Or. Octavian Petrus, AL I CuzA University, ROMANIA Or. Johan de Villiers, Fusion studies, AEC, SO AFRICA Prof. M.A. Helluerg, University of Notal, SO AFRICA C.I.E.M.A.T., Fusion Div. Library, SPain Dr. Lennart Stenfio, University of UMEA. SWEDEN Library, Royal Inst Tech, SWEDEN Prot. Hans Wilhelmson, Chalmers Univ Tech, SAEOEN Centre Phys des Plasmas, Ecole Polytech Fed, SwITZERLAind Bibliotheek, fom-inst Voor PIasma-Fysica, THE NETHERLANOS Dr. O.D. Ryutov, Siberian Acad Sci, USSR

Dr. G.A. Eliseey, Kurchatoy Institute, USSR Dr. V.A. Gluknikh, Inst Electroonysical toparjtus, USsA Or. V.T. Tolak, Inst. Phys, Tech. USsR Dr. L.M. Koyrizhnykh, Institute Gen. Jhysics, ijSR Nuclear Res. Estadishment, Julien Lta., H. GePMapuY Bibliothek, Inst. Fur Plasmaforsenung, n. GetMany

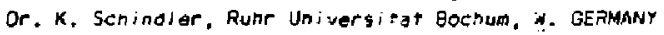
ASDEX Reoding Rm, IPP/Max-PlancX-instiqut t ur

Plasmaonysik, 'N. GeRMAnY Librarian, Max-Planck insti rut, H. GeRmaky Prof. R.K. Janev, inst Phys, rugoslavid 